\title{
Philosophy of Mathematics and Ontological Commitment
}

\author{
On Quine's and Vuillemin's Classifications*
}

\author{
Joseph Vidal-Rosset \\ University of Burgundy \\ 2, bd Gabriel \\ 21000 Dijon \\ France \\ Email: joseph.vidal-rosset@u-bourgogne.fr
}

\begin{abstract}
This paper concerns Quine's classification of philosophies of mathematics as sketched in "On what there is" and offers a new reading of Quine's view. In his famous paper Quine defines three positions: Realism, Conceptualism, and Nominalism. Each of them, he says, has its modern expression, respectively, in Logicism, Intuitionism, and Formalism. According to Quine these foundational positions can be accepted or rejected on a clear and objective basis, according to their distinctive ontological commitments. Consistent with his own criterion for ontological commitment (buttressed by his view on impredicative definitions), Quine adopts the Realist (or the Platonist) position in mathematics. Later, it is shown that genuine Intuitionism is not definable by Quine but is easily defined in Vuillemin's classification scheme (in What Are Philosophical Systems? C. U. P., 1986).
\end{abstract}

In one of his most famous papers, "On What There Is", Quine defines three 
ontological positions in philosophy of mathematics: Realism, Conceptualism, and Nominalism. Roughly speaking they can be associated, repectively, with three positions in contemporary philosophy of mathematics, namely: Logicism, Intuitionism, and Formalism:

Realism, as the word is used in connection with the mediaeval controversy of universals, is the Platonic doctrine that universals or abstract entities have being independently of the mind; the mind may discover them but cannot create them. Logicism, represented by Frege, Russell, Whitehead, Church and Carnap, condones the use of bound variables to refer to abstract entities known and unknown, specifiable, and unspecifiable, indiscriminately. Conceptualism holds that there are universals but they are mind-made. Intuitionism, espoused in modern times in one form or another by Poincaré, Brouwer, Weyl, and others, countenances the use of bound variables to refer to abstract entities only when those entities are capable of being cooked up individually from ingredients specified in advance. [...] Formalism, associated with the name of Hilbert, echoes Intuitionism in deploring the logicist's unbridled recourse to universals. But Formalism also finds Intuitionism unsatisfactory. The formalist might, like the logicist, object to the crippling of classical mathematics; or he might, like the nominalists of old, object to admitting abstract entities at all, even in the restrained sense of mind-made entities. The upshot is the same: the formalist keeps classical mathematics as a play of insignificant notations. ${ }^{1}$

According to Quine, the ontological dispute in modern philosophy of mathematics is clearer than the mediaeval controversy over universals because we possess a standard "to decide what a theory or form of discourse is committed to: a theory is committed to those and only those entities to which the bound variables of the theory must be capable of referring in order that affirmations made in the theory be true." 2

It is hard to imagine a simpler and clearer norm than the ontological commitment criterion. "Existence is what existential quantification expresses. There are things of kind $F$ if and only if $\exists x F x "{ }^{3}$ But Quine's classification would be unintelligible without a second criterion used but not explicitly formulated in "On what there is"; this second criterion has to do with impredicative definitions, definitions allowed by some philosophers and excluded by others. ${ }^{4}$ I shall rely in what follows on the definition of impredicativity given by Fraenkel: 
A definition of set is called impredicative if it contains a reference to a totality to which the set itself belongs. One may also say that a definition written in symbols is impredicative if it defines an object which is one of the values of a bound variable occurring in the defining expression. ${ }^{5}$

The paradoxical class $y$ of all classes $x$ that are not members of themselves is impredicatively defined. For if one lets the variable of quantification take $y$ as a value, $y$ is presupposed in defining $y$, and we get Russell's famous paradox. Since the members of the class $y$ are the non-self-members, the impredicative definition of $y$ qualifies $y$ as a member of itself if and only if it is not. ${ }^{6}$ Following Quine's example, we must, however, also insist on the harmlessness of the impredicative specification of the most typical Yale man who is defined by the averages of Yale scores including his own. ${ }^{7}$ So is it right to say, as Fraenkel does about the axiom of separation of Zermelo's set theory, that it has the awkward property of being impredicative ${ }^{8}$ Where is the awkwardness in impredicativity?

Why, then, did the great mathematician Poincaré refuse impredicative definitions? Saying that he did so because an impredicative definition entails a vicious circle is not helpful. In fact Poincaré distinguished predicative and nonpredicative classifications. The former cannot be changed by the introduction of new elements, the latter always runs the risk of being undone by their introduction. ${ }^{9}$ He rejected the existence of collections which are at once infinite and only impredicatively defined. ${ }^{10}$ The impredicative specification of Quine's most typical Yale man does not matter, but all the impredicative assumptions of class existence in Zermelo's set theory are quite disturbing. According to Poincaré, what is disturbing about the latter is the lack of security about the elements impredicatively introduced in infinite collections by the Zermeloian definitions of sets:

[Mr Zermelo] does not have any scruples in talking about the totality of objects that are elements of some Menge (set) $M$ and which, moreover, fulfill a certain condition. He thinks that he cannot have a Menge without having, therefore, all its elements at the same time. Among all these elements, he will choose those fulfilling a given condition, and he will be able to make this choice very quietly, without fear of being disturbed by the introduction of new and unexpected elements, because he already has all of these elements in hand. Setting down in advance his Menge $M$, he has put up an outer wall 
which checks intruders from outside. But he does not wonder whether he could have enclosed intruders inside with him. If the Menge $M$ has an infinity of elements, it does not mean that these elements can be thought to exist in advance all at the same time, but that new elements can continuously be born; they will be born inside the wall rather than outside, that is all. When I speak of all integers, I mean all the invented integers and all those which may be invented one day [...]. And the infinite is this "may be". [...] That is why I can't be satisfied by Mr Zermelo's axioms. They do not only seem to me obscure, but when asked whether they are free from contradiction, I am afraid I will not know what to answer. The author thought he avoided the paradox of the greatest cardinal by not allowing himself any speculation outside his well closed Menge-wall [...]. But if his pigeons are very well locked up, I am not sure that he has not set the cat to mind them. ${ }^{11}$

How, then, does Quine classify the three foundational doctrines with the help of his criterion of ontological commitment? As I said earlier, we need in fact not one kind of criterion but rather two in order to understand this tripartite classification. The ontological commitment of a mathematical theory can be decided by knowing if (a) the theory quantifies over sets which cannot be reduced to elements (i.e. the language of the theory cannot be translated into a first order logic system like LPC) and (b) at least one axiom of the theory is impredicative or involves a impredicative definition.

Since Zermelo's set theory satisfies both (a) and (b), it is a Platonist (or a Realist theory). Wang's set theory, a theory that assumes (a) but rejects (b), is conceptualist. On the other hand, Chihara interprets Wang's system as a no class theory, and believes that such a set theory satifies neither (a) nor (b), and is nevertheless strong enough for mathematics as well as being nominalist.

I turn now to the philosophical explanation of the use of the criteria for classification above, and to determining whether each position is well founded. Bernays rightly pointed out that Arithmetic presupposes at the very least the existence of the totality of integers. ${ }^{12}$ And that is a Platonistic presupposition. That is why the axiom of infinity and the axiom schema of separation of Zermelo's set theory make this theory Platonistic: the axiom of infinity is the postulate of infinite set, ${ }^{13}$ a set that can be considered as defined impredicatively via the axiom schema of separation. Finally, the undenumerability of the set of real numbers adds transcendence to the nonconstructivity: there is a nondenumerable infinity of real numbers in the 
Cantor-Zermelo universe and therefore an infinity of real numbers beyond the reach of our cognitive faculties. Conceptualism and Nominalism, on the other hand, reject mathematical transcendence as being philosophically prejudiced. But whereas Conceptualism considers sets or mathematical abstractions as results of mental activity, Nominalism denies any reality to mathematical objects and to any sort of universals.

According to Quine's criteria, a predicative theory is conceptualist because it quantifies over sets but avoids impredicative sets. On the other hand, a nominalistic theory of sets would have to paraphrase every quantification over sets into quantification over individual variables. ${ }^{14}$ From a Quinian point of view, Conceptualism (i.e. Predicativism, Constructivism), and Nominalism do not raise the same mathematical difficulties. It is impossible to formalize completely mathematical induction without second order quantification (i.e. quantification over predicates or sets). ${ }^{15}$ Therefore, the nominalistic attempt to translate all mathematical knowledge into a first order theory seems to be a waste of time. As Fraenkel said, ${ }^{16}$ "the difficulties in rephrasing all of classical mathematics in nominalistic terms seem, and probably are, insurmountable".

The conceptualist position appears less desperate. Predicative theories are founded on a progressive construction of sets: an infinite denumerable totality of sets (like all the positive integers) is given at the first level and all the sets of higher levels are defined by properties referring at most only to the totality of all sets of the level immediately lower to the one defined. The first predicative system was the ramified theory of types invented by Russell. ${ }^{17}$ But it is well known that Russell's addition of the axiom of reducibility, necessary to express, for example, Cantor's theorem, mathematical induction, or the theorem of the least upper bound, "has the effect of reinstating the whole Platonist logic of classes". ${ }^{18}$ In later predicative systems, the axiom of reducibility is absent and the progression of orders is made cumulative and transfinite. ${ }^{19}$ Lorenzen, Bishop, Wang and Feferman have succeeded in increasing the mathematical power of the ramified theory without the awkward axiom of reducibility. But under the restraint of predicativity, Cantor's theorem remains nondemonstrable, as does the nondenumerability of the set of real numbers. ${ }^{20}$ Thus, this philosophy of mathematics would more or less renounce a foundation for the totality of our mathematical knowledge.

Quine adopts mathematical Platonism, in spite of his initial nominalistic temp- 
tation. ${ }^{21}$ His philosophical position is based on a conservative Pragmatism. Because Zermelo's set theory is as strong as it is simple, and, with its cortège of specifiable and nonspecifiable real numbers, is required for the needs of natural sciences, Quine declares himself a reluctant Platonist in mathematics. ${ }^{22}$ To be is to be the value of a variable, a refrain tirelessly repeated by him, is the key to his mathematical Platonism: as long as a theory purporting to be a foundation for all the mathematical truths without quantification over impredicative sets is missing, it is precipitous to proclaim - as the pathetic title of a recent French book does - the defeat of Plato. If the objectual interpretation of the existential quantification (i.e. the standard reading of ' $(\exists x) F x$ ') is accepted, there is no way to avoid Quinian Platonism.

The objectual interpretation of the existential quantification is the crux of the matter. Quine believes that the question of the ontological commitment of a theory can really be asked only if a theory uses the classical form of quantification, or only if the theory is translated into this classical form. So the Quinian thesis of the indeterminacy of translation fits neatly with Quine's classification itself: Quine's system cannot express every system which uses a nonstandard interpretation of quantification (I will later show how to understand "nonstandard interpretation of quantification"), but is only able to translate such into a classical quantificational language. ${ }^{23}$ That is the reason why the set theory of Chihara should be classified as "an off-side Nominalism" because it involves a nonstandard interpretation of quantification. ${ }^{24}$ Though a refutation of Quine's Platonism could only be achieved within a Quinian framework, by using a nonstandard kind of quantification Chihara has constructed a predicative alternative to Platonism. Of course, this alternative needs a philosophical foundation in turn. If Nominalism is understood à la Chihara it cannot be adequately captured in Quine's terminology.Though Chihara's set theory gives off nominalistic signals, its interpretation of quantification is intuitionistic. But here the word 'intuitionistic' has a "non-Quinian sense".

In contrast to Quine, Vuillemin's classification of philosophical systems gives both an explanation and a correct formulation of the nonstandard interpretation of quantification theory presupposed by intuitionistic systems. Vuillemin bases his classification of philosophical systems on elementary sentences necessary to communicate perception. These are divided into propositions spontaneously picturing reality and judgments expressing the speaker's subjectivity. This division mirrors, 
respectively, dogmatic systems and systems of examination. The former describe the nature of reality without regard to subjectivity; Realism, Conceptualism and Nominalism are three dogmatic systems disagreeing about what there is.

The class of systems of examination, on the other hand, comprise two classes of rival systems. The first one accepts objective truth and goes beyond subjectivity, while the second strives hard to ruin belief in objective truth. The subjective series of judgments explains this internal opposition. Genuine Intuitionism is a compound of judgments of method; judgments of appearance are the foundation of Skepticism. Cartesian doubt is the philosophical paradigm of judgments of method. According to Vuillemin, a judgment of method in a genuine intuitionistic system is a sort of theoretical performative determining the ontology:

Judgments of method refer the existence of the object to the way in which it is known by the speaker. Thus every ontological posit is associated with a characteristic method of knowledge, without which it would make no sense. Let us call the possibility of referring the object to its appropriate method of knowledge the possibility of experience in general. The possibility of experience will become the unique highest category of an ontology, when, as highest principle, we admit that the existence of any object is contingent on the possibility of experience by which it is given. Intuitionism is the ontology which is expressed by this principle. ${ }^{25}$

We are now able to define the intuitionistic existential quantification in accordance with judgments of method: ' $(\exists x) F x$ ' no longer means "there is an object symbolized by the variable $x$ and fulfilling the $F$ property", but "there is $a$ proof that an object symbolized by $x$ is fulfilling the $F$ property". In other words, contrary to Platonism, genuine Intuitionism identifies truth with demonstrability, or, more precisely, only objects for which there is a positive proof of existence are accepted in the universe of discourse. Reductio ad absurdum alone cannot suffice to prove the existence of a mathematical object since the law of excluded middle is not mathematically valid from an intuitionistic point of view. We must therefore distinguish Conceptualism (which is mathematically expressed by predicativism) from genuine Intuitionism, defined by judgments of method, and, because of its nonstandard interpretation of quantification, necessarily overlooked by Quine. ${ }^{26}$

This is more than a simple terminological question. Genuine Intuitionism is 
essentially defined more by the rejection of the universality ofthe law of excluded middle than by the construction of predicative sets. This is so even though Beth has shown that Brouwer's set theory is akin to a ramified type theory. ${ }^{27}$ Last but not least, it is doubtful that the impredicativity of the most typical Yale man matters much from the perspective of a Poincarean philosophy of mathematics. The impredicative specification of an object does not worry Poincaré if its existence depends on something other than the impredicative specification alone. As Quine himself said, "to specify is not to create". Since the most typical Yale man can be constructed, nobody worries about the impredicativity involved in his definition. Intuitionism rejects the existence of infinite and nondenumerable totalities because it is beyond any decision method. "And where verification is missing, mathematicians get no further than philosophers". ${ }^{28}$ To follow Poincaré's thought, to be is to be not only the value of a variable, but the result of some calculation. To sum up, it is clear that the non-standard interpretation of the quantifiers is the most important aspect of Intuitionism, and, indeed, is possible in an impredicative domain. This tolerance of impredicativity is not a sign of any transcendance, but only a feature of a "semi-predicative system". ${ }^{29}$ With respect to Intuitionism, Vuillemin's method of classifcation reveals the limits of Quine's because his reading of philosophical grammar is also objectual and thus broader than Quine's ontological standard. Nevertheless, in terms of what Vuillemin calls "dogmatism" - philosophical systems paying no attention to subjective access to the truth - the Quinean criteria are the more simple and best suited to ontological analysis in philosophy of mathematics. They fit perfectly with Vuillemin's description of dogmatic philosophical systems, that is to say the class which captures Platonism, Conceptualism, and Nominalism. Platonism holds to the reality and the transcendence of Ideas, Conceptualism accepts the reality of ideas but denies their transcendence, and, Nominalism admits only universality of words or insigns, and reality is not ideas, but individuals or events. From a logical point of view, all dogmatic systems, in Vuillemin's classification, adopt unambiguously a standard interpretation of quantifiers, i.e. objectual quantification. 
(This paper, presented at the second European Congress for Analytic Philosophy (Leeds, 5-7 September 1996), is a synopsis of my Ph.D. thesis. It was presented in January 1996 at the University of Aix en Provence. I am very grateful to Professors Heinzmann, Michel, Pariente, E. Schwartz, and Vuillemin for their useful remarks. Last, thanks to my friends, Vincent Baby, Jimmy Plourde and Christian Desmier, who had the patience to read the first version of this text and to improve the English.

\section{NOTES}

1. Quine, 1953, pp. 14-15.

2. Ibid. pp. 13-14.

3. Quine, 1969, chap. 4: "Existence and quantification". In spite of the simplicity of this standard, Quine was compelled to make a distinction between the ontology and the ontological commitment of a theory (in Word and Object, Quine says "ontic commitment", but I prefer to use the original expression): "The ontology is the range of variables. Each of the various reinterpretations of the range (while keeping the interpretations of fixed predicates) might be compatible with the theory. But the theory is ontically committed to an object only if that object is common to all those ranges. And the theory is ontically committed to 'objects of such and such a kind', say dogs, just in case each of those ranges contains some dog or other." (Quine, in Davidson et al., 1969 , p. 315, originally published in Synthese, 19 (1968), pp. 264-321).

4. See Heinzmann, 1985, and Rivenc in Anthologie, pp. 393-398.

5. Fraenkel et al., 1958, second edition, p. 38.

6. Quine, 1963, p. 242.

7. Quine, 1963, p. 243.

8. Fraenkel et al., p. 38.

9. Poincaré, 1909, p. 401.

10. Quine has warned us about a misinterpretation of Poincaré's thought about impredicativity: "[...] what Poincaré criticized is not the definition of some special symbol as short for ' $\{x: x \notin x\}$ ', but rather the very assumption of the existence of a class $y$ fulfilling ' $(x)(x \in y$. $\equiv x \notin x)$ '. We shall do better to speak not of impredicative definition but of impredicative specification of classes, and, what is the crux of the matter, impredicative assumptions of class existence." (Quine, 1963, p. 242.)

11. Poincaré, 1909, p. 409.

12. Bernays, 1935, translated by C. D. Parsons in Benacerraf and Putnam, 1964, pp. 274-86.

13. $(\exists a)[\varnothing \in a \wedge(\forall x)(x \in a \Rightarrow(x \cup\{x\} \in a))]$. Schwartz, 1991, p. 51 .

14. Chihara, 1973, Chihara et al., 1975. 
15. Kleene, $1967, \S 38$ and $\S 53$.

16. Fraenkel et al., p. 333.

17. Russell \& Whitehead, 1910.

18. Quine, 1953, p. 127.

19. Wang, 1954, 1963.

20. This last point could be seen as a virtue of predicative systems ... from a conceptualist point of view.

21. Goodman and Quine, 1947, and see Quine, 1960, p. 269.

22. Quine, 1990, Ch. 2, § 11 .

23. Quine, 1970, Ch. 6, § “Intuitionism".

24. Chihara, 1973, pp. 210-211.

25. Vuillemin, 1986, p. 125.

26. In "Logic and the reification of universals" Quine notices in a footnote the distinction beetwen these two philosophical systems: "The conceptualist position in the foundations of mathematics is sometimes called Intuitionism, in a broad sense of the term. Under stricter usage 'Intuitionism' refers only to Brouwer and Heyting's special brand of Conceptualism, which suspends the law of excluded middle." (Quine, 1953, p. 125, fn. 21.)

27. Beth, 1959, pp. 443-444.

28. Poincaré, 1913.

29. Kreisel, 1960.

\section{References}

Anthologie (1850-1914): Institut d'Histoire et Philosophie des Sciences et des Techniques, Logique et Fondement des mathématiques, Anthologie (1850-1914), Rivenc F. et de Rouilhan P. eds., Paris, Payot, 1992.

Benacerraf P. \& Putnam H.,

- 1964: Philosophy of Mathematics: Selected Readings, Englewood Cliffs, New Jersey, Prentice-Hall

Bernays P.,

-1935: "Sur le Platonisme dans les Mathématiques", L'enseignement mathématique, $\mathrm{n}^{\circ}$ 34,1935 , pp. 52-69, translated by C. D. Parsons in Benacerraf and Putnam, 1964, pp. $274-86$.

Beth E. W.,

- 1959: The Foundations of Mathematics, Amsterdam, North-Holland. 
Chihara C. S.,

- 1973: Ontology and the Vicious-Circle Principle, New York, Cornell University Press. 9 Chihara C. S., Lin Y., Schaffter T.,

- 1975: "A formalization of a nominalistic set theory", Journal of Philosophical Logic, $\mathrm{n}^{\circ}$ 4, pp. 155-169.

Davidson, Donald, and Jaako Hintikka, eds.,

- 1969: Words and Objections: Essays on the Work of W. V. Quine, Dordrecht, Holland: D. Reidel.

Feferman S.,

- 1964: "Systems of predicative analysis", Journal of Symbolic Logic, n 29, pp. 1-30.

Fraenkel A.,

- 1922: "Zu den Grundlagen der Cantor-Zermeloschen Mengenlehre", in Mathematische Annalen $\mathrm{n}^{\circ}$ 86, pp. 230-237.

- 1935: "Sur la notion d'existence dans les mathématiques", L'enseignement mathématique, $n^{\circ}$ 34, pp. 18-31.

Fraenkel, Bar-Hillel, Levy,

- 1958: Foundations of Mathematics, North Holland, Amsterdam, 1958, second edition $1973,1984$.

Goodman \& Quine,

- 1947: "Steps toward a constructive Nominalism", Journal of Symbolic Logic, $\mathrm{n}^{\circ} 12$, pp. 105-122.

Heinzmann G.,

- 1985: Entre intuition et analyse, Poincaré et le concept de prédicativité, Paris, A. Blanchard.

Kleene S. C.,

- 1967: Mathematical Logic, New-York, John Wiley \& Sons. Kreisel G.,

- 1960: "La prédicativité, Bull. Math. de France, n 88, pp. 371-391. Lorenzen, 10

- 1951: "Algebraische und Logistische Unterschungen über Freie Verbände”, in Journal of Symbolic Logic, 16, pp. 81-106.

Poincaré $\mathrm{H}$.,

- 1909: "La Logique de l' infini", Revue de Métaphysique et de Morale, (t. XVII, 1909), in Derniéres Pensées (1913), and in Anthologie, (extracts) pp. 391-414.

- 1913:Derniéres Pensées, Paris, Flammarion.

Quine, W. v. O.,

- 1936: "On the axiom of reducibility", in Mind 45, pp. 498-500.

- 1937: “On Cantor's Theorem", Journal of Symbolic Logic, Vol. 2, N 3.

- 1953: From a Logical Point of View, Nine Logico-Philosophical Essays, Cambridge Mass., Harvard University Press. 
- 1960: Word \& Object, Cambridge, Mass., The M.I.T. Press. (Le Mot et la Chose, traduction Gochet, Paris, Flammarion., 1978.)

- 1963: Set Theory and Its Logic, Cambridge Mass., Harvard University Press.

- 1969: Ontological Relativity and Others Essays, New-York, London, Columbia University Press. (Relativité de l'ontologie et autres Essais, traduction Largeault, Aubier-Montaigne, Paris, 1977.)

- 1970: Philosophy of Logic, Prentice Hall. (Philosophie de la logique, traduction Largeault Aubier-Montaigne, Paris, 1975.)

- 1987: Quiddities, An Intermittently Philosophical Dictionary, Cambridge Mass., The Belknap Press of Harvard University Press. (Quiddités, Dictionnaire philosophique par intermittence, traduction Goy-Blanquet et Marchaisse, Paris, Seuil, 1992.)

- 1990: Pursuit of Truth, Cambridge Mass., Harvard University Press. (La poursuite de la vérité, traduction Clavelin, Paris, Seuil, 1993.)

Russell \& Whitehead,

- 1910: Principia Mathemathica, London, Cambridge University Press. (Trad. fr. de l'Introduction in Russell, Ecrits de Logique Philosophique, traduction Roy, Paris, P.U.F., 1989, pp. 221-334.)

Schwartz L.,

- 1991, Analyse I, Paris, Hermann.

Vuillemin J.,

- 1981: "Trois philosophes intuitionnistes: Epicure, Descartes, Kant" in Dialectica, vol. $35, \mathrm{n}^{\circ} 1-2$, pp. $21-41$.

- 1984: "Les formes fondamentales de la prédication: un essai de classification", Recherches sur la philosophie et le langage, cahier $n^{\circ} 4$ du Goupe de Recherches sur la Philosophie et le Langage, Université des siences sociales, Grenoble, Paris, Vrin.

- 1984 a: Nécessité ou Contingence, Paris, éditions de Minuit.

- 1986: What Are Philosophical systems? , Cambridge University Press.

Wang H.,

- 1954: "The formalization of mathematics", Journal of Symbolic Logic, 19, pp. 241-266, also in 63 , pp. 559-584.

- 1963: A Survey of Mathematical Logic, Amsterdam, North Holland Publishing Company.

Wittgenstein L.,

- 1922: Tracatus Logico-Philosophicus, Routledge \& Keagan Paul Ltd, London, 1922. (Tracatus Logico-Philosophicus, traduction Granger, Paris, Gallimard, 1993.) 